\title{
Estudantes adultos e idosos pouco escolarizados e cultura digital: algumas provocações ${ }^{1}$
}

\section{Resumo}

Este artigo enfoca a relação entre estudantes pouco escolarizados e cultura digital. Inicialmente, buscamos enfatizar que o vínculo entre o ser humano e a tecnologia, do ponto de vista do filósofo Álvaro Vieira Pinto, é uma relação ontológica. Entretanto, se a cultura digital vem revolucionar a informação e a comunicação, ampliando as janelas do mundo, é vigente a crença de que adultos e idosos pouco escolarizados estariam à margem do processo. Buscamos problematizar este aspecto, trazendo breve relato de uma experiência tecnológica levada a cabo com estudantes em processo de alfabetização em uma turma da Educação de Jovens e Adultos de Florianópolis. Concluímos que há barreiras à participação dos estudantes mencionados na cultura digital, porém nosso pressuposto é de que, considerando seus saberes da experiência, não é tão simples apenas falar em exclusão ou marginalidade. Para nossas reflexões, recorremos a autores como Manuel Castells, Jorge Larrosa Bondía, Boaventura de Sousa Santos, Paulo Freire e Carmen Cavaco, além de Álvaro Vieira Pinto.

Palavras-chave: Tecnologia; Cultura digital; Adultos e idosos pouco escolarizados.

\section{Deisi Cord}

Doutoranda em Educação na Universidade do Estado de Santa Catarina - UDESC. Brasil deisicord@gmail.co

\section{Sonia Maria Martins de Melo}

Doutora em Educação pela Pontifícia Universidade Católica do Rio Grande do Sul - PUCRS. Professora da Universidade do Estado de Santa Catarina UDESC. Brasil soniademelo@gmail.com

\footnotetext{
${ }^{1}$ Reflexões a partir do Projeto de pesquisa de doutorado em desenvolvimento, no Programa de Pós Graduação em Educação da Universidade do Estado de Santa Catarina - UDESC, linha Educação, Comunicação e Tecnologia, com apoio da Fundação de Amparo à Pesquisa e Inovação do Estado de Santa Catarina - FAPESC.
} 


\title{
Adults and elderly students with little formal education and digital culture:some teasings
}

\begin{abstract}
This article focuses on the relation between students with little formal education and digital culture. First of all, we would like to emphazise the bond between human being and technology, from the point of view of the philosopher Alvaro Vieira Pinto, That this is an ontological relationship. However, if the digital culture is revolutionizing the information and the communication, broading the windows of the world, the current belief that adults and elderly students with little formal education would be in the outskirts of the digital culture. We want to discuss this subject, bringing a brief account about of a technological experience carried out with students in literacy process, in class of Youth and Adult Education of Florianópolis. We have come to a conclusion that there are barriers to the participation of the students mentioned in the digital culture, although our premise is that, taking into account, their experience in the subject, it is not so easy to talk about exclusion or marginality. In order to help us thinking about the problem in question, we turn to authors such as Manuel Castells, Jorge LarrosaBondía, Boaventura de Sousa Santos, Paulo Freire, Carmen Cavaco and Álvaro Vieira Pinto.
\end{abstract}

Keywords: Technology; Digital culture; Adults and elderly students with little formal education.

\section{Para citar este artigo:}

CORD, Deisi; MELO, Sonia Maria Martins de. Estudantes adultos e idosos pouco escolarizados e cultura digital: algumas provocações. Revista PerCursos. Florianópolis, v. 16, n.31, p. 118 -136, maio/ago. 2015.

\author{
DOI: $\mathbf{1 0 . 5 9 6 5 / 1 9 8 4 7 2 4 6 1 6 3 1 2 0 1 5 1 1 8}$ \\ http://dx.doi.org/10.5965/1984724616312015118
}




\section{Para início de conversa...}

Falar, hoje, em tecnologias digitais ao alcance de todos, é lugar comum. Falar sobre o absurdo de existirem, no momento, cerca de 800 milhões de analfabetos no mundo, também o é. Do entrecruzamento dos dois fenômenos, o que facilmente é afirmado é que pessoas pouco escolarizadas (entre elas os analfabetos) estão “excluídas" dos avanços tecnológicos da modernidade porque, de forma geral, não têm condições de compreender a complexidade destas tecnologias.

De acordo com Cavaco (2009), a UNESCO, no afã de conquistar a parceria de países que se mobilizassem em prol da diminuição do analfabetismo, teve o mérito de afirmar a concepção de analfabetismo como problema social e político, porém cometeu o erro de relacionar o sujeito analfabeto à carência, ao déficit, à ausência de competências, provocando a estigmatização deste sujeito. Para a autora,

A construção social do problema do analfabetismo, como estratégia para dar projeção e sensibilizar os governos e os cidadãos, baseou-se nas consequências negativas resultantes da ausência de competências de leitura e escrita, a nível individual, social e econômico. (CAVACO, 2009, p. 113)

Todavia, ao interagirmos, em nossa função docente, com os sujeitos da Educação de Jovens e Adultos, constatamos que a carência, os déficits e, portanto, a exclusão do acesso às tecnologias não são passíveis de serem afirmados em toda a sua extensão. Há pontos de encontro e de distanciamento entre os sujeitos pouco escolarizados e as tecnologias atuais. $\mathrm{E}$ há, obviamente, pessoas alfabetizadas e letradas que também se aproximam e distanciam das mesmas tecnologias. Vieira Pinto explica que, enquanto educadores e legisladores considerarem o analfabetismo uma deficiência a ser erradicada, as políticas públicas voltadas ao setor trilharão pelo caminho errado, tendo em vista que "é de fato uma deficiência culturalmente grave, mas que nada tem de sociologicamente anormal” (VIEIRA PINTO, 2010, p. 93).

Deste ponto de vista, o que temos é um paradoxo da modernidade? Da pósmodernidade? Pouco importa saber essa definição aos sujeitos que o vivem. Pouco ou 
nenhum sentido faz, aos adultos e idosos pouco escolarizados, o fato de viverem um paradoxo. Em suas vidas produzem, cotidianamente, artifícios, artimanhas, saídas complexas e eficazes para os desafios por não dominarem a escrita. Particularmente em contextos urbanos, estes sujeitos e as tecnologias avançadas coexistem e parece haver, observando-se empiricamente, um usufruto: consomem/utilizam, sim, tecnologias, que os têm favorecido em vários aspectos de suas vidas. Urgente se torna entendermos como o fazem, e como compreendem esta relação, apesar de sua condição de pouca escolarização.

É interessante notar que este parece ser um problema que não preocupa/afeta a indústria do setor que, diuturnamente, injeta mais e mais artefatos tecnológicos no cotidiano das sociedades. A indústria não parece, de fato, estar muito preocupada se os consumidores têm ou não domínio de certos pré-requisitos para que consigam usufruir de seus produtos. E o que se verifica, a partir do sucesso das vendas de produtos característicos da cultura digital é que, de fato, muitos consomem, apesar da distância enfatizada por alguns setores, como a própria escola, entre os que dominam e o que têm um distanciamento de domínio de conhecimentos "a priori".

Desta perspectiva, como lidariam os milhões de analfabetos no mundo, com a onda das tecnologias digitais? Estariam simplesmente excluídos? Acreditamos que não é assim tão simples. Mas, se não estão excluídos (e não estão, basta olhar com olhos de quem quer ver), como vencem as barreiras “impostas" pela cultura letrada para se inserirem neste contexto?

Este artigo é parte das reflexões de uma pesquisa de doutorado em andamento no Programa de Pós-Graduação em Educação da Universidade do Estado de Santa Catarina. A pesquisa, com base nos pressupostos do materialismo histórico-dialético busca, com estudantes adultos e idosos do I Segmento ${ }^{2}$ da Educação de Jovens e Adultos de

\footnotetext{
${ }^{2}$ A Educação de Jovens e Adultos (EJA) do município de Florianópolis está estruturada em dois segmentos. O I Segmento corresponde aos anos iniciais do ensino fundamental, com ênfase no processo de aquisição da leitura e escrita. Já o II Segmento corresponde aos anos finais do ensino fundamental e estrutura-se a partir da metodologia da pesquisa como princípio educativo.
} 
Florianópolis, sua compreensão acerca da relação entre os sujeitos pouco escolarizados e a cultura digital.

Tendo em vista que a pesquisa de doutorado sobre a temática encontra-se ainda em andamento, neste artigo busca-se apresentar dados resultantes de pesquisa bibliográfica -de onde foram trabalhadas e problematizadas categorias que são inerentes às relações entre o ser humano e a tecnologia e as transformações ocorridas no seu cotidiano com o advento das tecnologias digitais, ensejando o que se vem denominando de "cultura digital”, bem como registram-se reflexões crítico-amorosas, como diria Paulo Freire, sobre uma caminhada pedagógica alternativa junto a uma turma de EJA em que os próprios sujeitos fizeram uso de tecnologias para ampliarem sua voz.

De forma mais específica, dentro deste panorama, nossas reflexões neste texto buscam subsidiar a afirmação de que os sujeitos pouco escolarizados, apesar das dificuldades inerentes à sua condição, participam sim da cultura digital, participação essa para a qual, num olhar aligeirado, parece tornar imprescindível o domínio ao menos elementar dos signos da cultura letrada. Informar-se e comunicar-se, nesta cultura digital, parece trazer embutido o saber ler e escrever, padrão esperado de uma escolarização formal e sistemática, mas afirmamos que esse saber ler e escrever nessa cultura digital é, também e, principalmente, saber ler e viver o mundo.

\section{O ser humano e a tecnologia: uma relação ontológica}

“[...] un nuevo pedazo frágil y precario de ti mismo, algo que es tuyo, pero no es tu cuerpo [...]". Neste trecho de Preámbulo a las instrucciones para dar cuerda al reloj ${ }^{3}$, Julio Cortázar (s/d) retrata nossa relação com um artefato tecnológico, algo com o que tão naturalmente compartilhamos complexos sentidos e significados. Artefatos que nem sempre são assim frágeis ou precários, mas que se tornam, indubitavelmente, um pedaço de nós. Qual pedaço? O que seria essa "coisa" que inventamos, produzimos, consumimos e que nos

\footnotetext{
${ }^{3}$ [...] um novo pedaço frágil e precário de ti mesmo, algo que é teu, mas não é o teu corpo [...]. Tradução livre das autoras. $O$ original pode ser encontrado em CORTÁZAR, Julio. Preámbulo a las instrucciones para dar cuerda al reloj Disponível em: http://www.me.gov.ar/efeme/cortazar/reloj.html.
} 
(re)inventa, nos (re)produz e, por que não: também nos consome? Que, paulatinamente, se torna parte importante de nós? Algo que se insere no nosso cotidiano, queiramos ou não, tenhamos ou não consciência. Outras vezes, mais do que inserir-se, torna-se o próprio cotidiano. Transforma-o. Traz cores, nuances, conceitos. Inscreve-se em formas de ser e estar no mundo. Por vezes é fim, é objetivo, é meta. Inventada por humanos para humanos, hoje assume centralidade tal que muitas vezes ganha status de protagonista.

A partir de onde podemos falar da tecnologia e sua relação com o homem? De diversos lugares ou não lugares, diversas perspectivas. É possível afirmar que elas “dominam o mundo”. Também é factível interrogar até onde poderemos ir. Todavia, Castells considera que a “mão" humana a tudo produz, sendo importante não perdermos de vista esta afirmação:

[...] computadores, sistemas de comunicação, decodificação e programação genética são todos amplificadores e extensões da mente humana. O que pensamos e como pensamos é expresso em bens, serviços, produção material e intelectual, sejam alimentos, moradia, sistemas de transporte e comunicação, mísseis, saúde, educação ou imagens. (CASTELLS, 1999, p. 69)

Dessa forma, para onde quer que olhemos, não cometeremos equívocos ou exageros ao afirmar que a tecnologia é inerente ao ser humano. Sempre esteve na sua história, no seu agir. Confunde-se com o trabalho, outra das categorias que nos é constitutiva. Sempre foi motivo de transformações. Por muitas vezes, tecnologia é a causa de disputas, parceira de conquistas, provocadora de diferenças (de acessos, de oportunidades, de exploração, de cobiça, de hierarquias...), mas em maior ou menor grau, está distribuída onde quer que haja seres humanos.

A concepção de história que perpassa o pensamento do materialismo histórico-dialético não é a ideia de progresso, no sentido de melhor, mais aperfeiçoado. Mas a ideia de que pelo trabalho, pelo reconhecimento de novas necessidades, temos uma complexificação cada vez maior de nossas próprias criações. É da história do ser humano, criar sempre mais complexidade. É ontologicamente próprio ao ser social, porque trabalha, porque tem necessidades e porque ao suprir necessidades, de imediato, cria novas e, portanto, cria outros instrumentos, outras e novas técnicas e tecnologias. 
O filósofo brasileiro Álvaro Vieira Pinto concebe, em sua obra "O Conceito de Tecnologia”, que a técnica faz o ser humano na medida em que este a realiza: “o principal produto do homem é ele mesmo" (VIEIRA PINTO, 2005, p. 149). Para este autor, técnica e tecnologia são formas de acesso aos bens produzidos pela humanidade e também não acesso, considerando-se a relação entre países centrais e periféricos. Sendo símbolo de poder, Castells considera que "as elites aprendem fazendo e com isso modificam as aplicações da tecnologia, enquanto a maior parte das pessoas aprende usando e, assim, permanecem dentro dos limites do pacote da tecnologia" (CASTELLS, 1999, p. 73). Já Vieira Pinto defende, neste sentido, que a tecnologia é criação humana e não pode ser expropriada de qualquer ser humano por questões de poder. Segundo o autor,

Se a técnica configura um dado da realidade objetiva, um produto da percepção humana, que retorna ao mundo em forma de ação, materializado em instrumentos e máquinas, e entregue à transmissão cultural, compreendese que tenha obrigatoriamente de haver a ciência que o abrange e explora, dando em resultado um conjunto de formulações teóricas, recheadas de complexo e rico conteúdo epistemológico. Tal ciência deve ser chamada 'tecnologia'. (VIEIRA PINTO, 2005, p. 221)

Este autor entende que a técnica é a forma, por meio do trabalho, de o ser humano gerar sua subsistência. Já a tecnologia englobaria a reflexão sobre a técnica, sua teorização, o pensar sobre. Para Vieira Pinto, cultura é tecnologia e a técnica está subordinada a esta, tendo em vista que o humano desenvolve-se por meio da cultura, das formas de ser e estar no mundo, do relacionar-se com a natureza e transformá-la em benefício de suas necessidades. Cultura é, assim, a possibilidade de produzir, que transforma o mundo à imagem do que o humano idealiza, a realidade física e social. Nesse processo, cria a sua existência, modifica a si próprio, inscreve-se na historicidade e necessita conhecer para subsistir.

Vieira Pinto é generoso com as possibilidades emancipatórias traduzidas pelas tecnologias para a libertação da humanidade do trabalho alienado sem, contudo, ser um mero entusiasta desta via. Compreende que é possível, ao trabalhador, dominar a técnica e não somente reproduzi-la. Com suas reflexões, nos traz a razão e a potência humanas de inventar e 
reinventar técnicas e tecnologias. E, por que não, inventar e reinventar maneiras de utilizar as tecnologias existentes, criadas por outros.

O filósofo põe em xeque as tentativas de adjetivação da tecnologia, que resultariam em subjetivação humana, mas não nega a ela sua capacidade de nos transformar enquanto a transformamos (VIEIRA PINTO, 2005). Tecnologia é, assim, perpassando o tempo histórico (e pré-histórico) da humanidade, política, ideologia, artefato, linguagem, cultura, instrumento... Dependendo de para onde se olhe, é sempre algo diferente. Um caleidoscópio de efeitos, causas, processos, mediações. É ontológica ao ser humano, porque o define enquanto por ele é definida, considerando-se seu papel na constituição de individualidades, subjetividades, coletividades e, por conseguinte, culturas.

Nesse cenário, as tecnologias digitais, inscritas na cultura digital, trazem em si a possibilidade de "alargamento do mundo" como nunca antes em outros momentos históricos.

\section{A cultura digital: um complexo de sentidos e significados}

Diuturnamente, somos lembrados de que viver em uma cultura que se proclama digital pressupõe protagonismo, autoria, aprendizagem ativa e reflexiva. Que é fundamental agirmos em cooperação, trabalharmos em rede. O tempo todo e em qualquer contexto, são correntes expressões como: compartilhamento, desterritorialidade, produção e distribuição de conteúdo, fluidez. E muito do que se afirma diz respeito às tecnologias digitais. Para Boaventura de Sousa Santos (2001, p. 07), "somos todos protagonistas e produtos dessa nova ordem, testemunhos vivos das transformações que ela produziu". Assim têm sido nossos dias: anúncios de uma revolução cultural tal que, para se conseguir bem viver, são necessárias muitas (e cada vez mais outras) competências e habilidades.

Gilberto Gil, enquanto esteve à frente do Ministério da Cultura, fez uma interessante reflexão acerca do momento em que vivemos. Para Gil, 
Novas e velhas tradições, signos locais e globais, linguagens de todos os cantos são bem-vindos a este curto-circuito antropológico. A cultura deve ser pensada neste jogo, nessa dialética permanente entre tradição e invenção, nos cruzamentos entre matrizes muitas vezes milenares e tecnologias de ponta, nas três dimensões básicas de sua existência: a dimensão simbólica, a dimensão de cidadania e inclusão, e a dimensão econômica. [...] (GIL, 2004, sem página)

A partir do que afirma Gil, é possível concebermos a cultura digital não apenas como amplo acesso às tecnologias digitais, mas como um sistema complexo carregado de símbolos, valores e práticas diversas. De cultura, por fim.

Cultura digital é um conceito novo. Parte da ideia de que a revolução das tecnologias digitais é, em essência, cultural. O que está implicado aqui é que o uso de tecnologia digital muda os comportamentos. O uso pleno da internet e do software livre cria fantásticas possibilidades de democratizar os acessos à informação e ao conhecimento, maximizar os potenciais dos bens e serviços culturais, amplificar os valores que formam o nosso repertório comum e, portanto, a nossa cultura, e potencializar também a produção cultural, criando inclusive novas formas de arte 4 . (GIL, 2004, sem página)

O fato de podermos, para além do consumo, também produzir conteúdo e distribuí-lo em rede, de forma multidirecional, certamente é uma profunda modificação nas relações sociais, contribuindo para as transformações culturais vigentes. A mobilidade que ganhamos, por exemplo, com os smartphones, a partir da convergência que integra vários recursos em um único aparelho, nos traz a ideia de uma revolução, principalmente nas comunicações, mas que reverbera em todas as áreas da vida em sociedade.

Podemos considerar que a cultura digital é uma tangível potencialização da cultura grafocêntrica, tendo a linguagem escrita um papel central nesse processo. A

\footnotetext{
${ }^{4}$ Trecho da aula magna de Gilberto Gil, então Ministro da Cultura, proferida na Universidade de São Paulo em 10 de agosto de 2004. Disponível em: http://www.cultura.gov.br/noticias-ancine1/lasset_publisher/QRV $5 \mathrm{ftQkjXuV/content/ministro-da-cultura-gilberto-gil-em-aula-magna-na-universidade-de-}$ sao-paulo-usp-/11025
} 
complexidade do mundo atual, inscrito nesta cultura digital, já se configura de difícil acompanhamento a quem domina as ferramentas de leitura e escrita. Nesse contexto, como será viver em ainda maior "descompasso com o mundo"? Como será, para sujeitos pouco escolarizados, ver-se na cultura digital? Considerar-se-ão à margem? Ou conseguem também se relacionar, comunicar e interagir de modo a manter o protagonismo de suas ações? Como os sujeitos pouco escolarizados se inserem na cultura digital? Como compreendem essa inserção e essas relações?

De acordo com Castells (1999, p. 68), “[...] todas [as revoluções tecnológicas] são caracterizadas por sua penetrabilidade ${ }^{5}$, ou seja, por sua penetração em todos os domínios da atividade humana, não como fonte exógena de impacto, mas como o tecido em que essa atividade é exercida". No meio dessa revolução, encontram-se os sujeitos pouco escolarizados, envolvidos em velhos estigmas que, via de regra, colocam em dúvida a sua (boa) inserção nas complexas relações sociais. E a cultura digital não fica de fora. Quase naturalmente pode-se afirmar que estes sujeitos, por sua pouca escolarização, não se inserem satisfatoriamente no movimento fluído e agitado, comunicativo e produtor de conteúdo que caracterizam esta cultura.

Porém, é pertinente observarmos as formas com que os sujeitos destituídos de conhecimento escolarizado (apesar de estarem, de certo modo, impregnados da cultura escolar) encaram o mundo e suas coisas, suas relações. Como estes sujeitos, submersos que estão na cultura grafocêntrica, conseguem (con)viver mesmo não dominando, a contento, a leitura e escrita e, com esta situação, serem considerados excluídos de ampla e complexa rede de sentidos e significados?

Consideramos, porém, que podem ser aligeiradas as conclusões de que os sujeitos pouco escolarizados estão à margem da cultura digital, tendo em vista que ao desconhecermos as estratégias utilizadas por eles para conseguirem (con)viver na cultura letrada, podemos também negligenciar aspectos fundamentais de sua maneira de aprender a viver no mundo. Quando convivemos com estes sujeitos, muito mais do que constatar a simples ausência de conhecimento, deparamo-nos com alternativas aos ditos

\footnotetext{
5 Destaque no original.
} 
não saberes. Por essa razão é necessário observarmos e desvelarmos o quanto os discursos hegemônicos desqualificam (e desconhecem) as pessoas pouco escolarizadas.

Sobre este ponto, o de desconsiderar a caminhada dos sujeitos no seu processo de aprendizagem, Cavaco (2009) aponta que há um paradoxo construído a partir da necessidade de se valorizar a escolarização visando o desenvolvimento das nações. Neste processo, no Brasil, a partir do século XX foi construído um discurso que até a atualidade embasa campanhas de alfabetização que se propõem a "erradicar" o analfabetismo como uma doença cujos principais responsáveis são os próprios indivíduos "acometidos" por tal chaga.

Na perspectiva de se contrapor a essa ideia de analfabetismo como uma praga a ser erradicada é que apresentaremos a seguir um relato crítico-reflexivo de uma caminhada pedagógica vivenciada pela hoje doutoranda como expressão das possibilidades de desconstrução dessa perversa desqualificação.

\section{Uma experiência ${ }^{6}$ tecnológica desenvolvida por sujeitos pouco escolarizados como um convite para novas reflexões}

Brevemente, relatamos a partir de agora uma experiência tecnológica levada a cabo com uma turma de I Segmento do Núcleo Sul I7, da EJA de Florianópolis, localizado no Bairro da Costeira do Pirajubaé, no primeiro semestre de 2013, na qual uma das autoras era a docente.

Uma pequena turma, com frequência satisfatória de cerca de treze alunos com idades entre 16 e 72 anos, que teve muito movimento, pois enquanto alguns estudantes frequentavam-na de forma permanente, outros foram embora e novos vieram. Alguns

\footnotetext{
${ }^{6} \mathrm{O}$ termo "experiência", neste texto, é usado no sentido que lhe atribui Bondía: algo que nos acontece e requer uma interrupção - parar para pensar, para olhar, escutar, sentir, calar, ser paciente, dar-se tempo e espaço, incorporar o novo conhecimento. Ver: BONDIA, Jorge Larrosa. Experiência e alteridade em educação. Revista Reflexão e Ação, Santa Cruz do Sul, v.19, n2, p.04-27, jul./dez. 2011. p. 4. Disponível em https://online.unisc.br/seer/index.php/reflex/article/view/2444/1898.

${ }^{7}$ A Educação de Jovens e Adultos do município de Florianópolis se organiza a partir de núcleos distribuídos pelos bairros da cidade, via de regra, sediados em escolas municipais. Há turmas de I e II Segmentos, de acordo com a demanda apresentada, sendo necessário um mínimo de quinze estudantes matriculados para iniciar uma turma. A cada ano, os núcleos podem mudar de lugar, visando atender à demanda local de matrículas.
} 
vieram/partiram/voltaram, de acordo com o que a vida lhes permitiu — o cuidado com os filhos, a (não) anuência dos maridos, a participação quase diária em cultos religiosos, a mudança de horário do emprego... Muita coisa foi acontecendo e transformando a rotina destes jovens, adultos e idosos estudantes da EJA.

Desde o início do ano, eram levadas muito a sério as histórias de vida dos estudantes da turma. Cada um compartilhou o que quis de suas experiências. Esse recurso foi utilizado com frequência durante o trabalho com os mais variados conteúdos, tendo em vista que as diferentes oportunidades que cada um teve ao longo da vida eram bem-vindas ao serem inseridas no planejamento. Os jovens pouco queriam falar, mas gostavam de ouvir. Quem mais gostava de socializar fatos de sua vida eram as idosas, duas ao todo.

Em julho daquele ano, a Secretaria Municipal de Educação de Florianópolis iria organizar o evento "EJA na Rua”, para promover esta modalidade entre a população, visando ampliar o número de matrículas. De pronto, aceitamos participar. Mas como? Com o quê? Escrever, todavia, seria um processo longo, doloroso para eles, já que a maioria estava se iniciando na escrita autônoma. Discutimos a logística do evento na praça: os transeuntes parariam para ler mal traçadas linhas a lápis? Compreenderiam a mensagem? Aliás, qual mensagem o grupo gostaria de transmitir ao público? Então Regina, uma das estudantes adultas, resolveu o problema: "Se é para aumentar o número de estudantes na EJA, que tal fazermos um convite para que venham conhecer nossas escolas?".

Perfeito! E por que não fazerem o convite de forma digital, recorrendo às tecnologias de informação e comunicação? Este desafio foi proposto pela então docente, hoje doutoranda, tendo em vista que, desde o início do ano, uma questão a incomodava: vários integrantes do grupo não gostavam de ir para a sala informatizada, pois não tinham paciência para usar o computador. Por muitas vezes, a docente cedeu. Em outras, as atividades foram realizadas por lá. E, nesses momentos, eram comuns conversas sobre tecnologias em geral, seu uso e acessibilidade, de onde surgiram as seguintes informações: todos tinham telefone celular. A maioria possuía computador em casa. Alguns não o utilizavam, enquanto outros circulavam em redes sociais, postavam 
imagens, mensagens, faziam pesquisas, navegavam...

Havia um estudante, em particular, que intrigava a docente: não conseguia reconhecer sequer as letras do próprio nome, porém passava todo o período de aula manipulando o seu aparelho celular, naturalmente, recebendo e respondendo mensagens. Nunca lhe foi perguntado sobre o teor das mesmas, mas a curiosidade permaneceu: o que comunicava? Com quem? Como? Para quê? O fato é que tinha esta necessidade e a supria, de seu modo particular, certamente recorrendo a diversas e elaboradas estratégias para ser e estar no mundo letrado.

Entre as tecnologias de comunicação e informação, a mais popular no grupo era a televisão. Todos assistem novelas, noticiários, programas de entretenimento... Menos uma das idosas que, por influência de sua religião, é desaconselhada de tal prática. Mas essa tecnologia, a televisão, via de regra, não promove a troca, não prima pela produção de conteúdos argumentativos, não traz espaço para as contribuições dos expectadores. Não há desafios à condição de não leitores e não escritores, tendo em vista que são, somente, receptores passivos nesse processo, como qualquer outro expectador o é.

Para Kenski (2007, p. 39),

a mídia televisiva - como todas as demais formas midiáticas nãointerativas - encaminha a comunicação de forma unidirecional, ou seja, de um único emissor para muitos espectadores. Mesmo nos atuais programas interativos de televisão, o espectador pode opinar e interagir dentro de um limite definido de opções dispostas pela programação.

Sabemos que há, nas grades de programação das emissoras, algumas possibilidades de interação entre programa/expectador. Todavia, são aspectos esporádicos e, no conjunto das atividades televisivas, permanecem irrelevantes à condição de pouca escolarização aqui discutida. A passividade, como outras estratégias televisivas, pode ter, entre outras razões, sua explicação no "conforto" de ser cooptado sem percebê-lo.

Da convivência e das conversas com os estudantes sobre tecnologias, aos poucos 
foram sendo desmistificadas algumas questões que, parece, frequentam o imaginário dos letrados/alfabetizados: sim, o analfabeto "se vira" com as tecnologias, descobre como utilizá-las e as incorpora no seu dia-a-dia. Nas palavras de Paulo Freire (1977, p. 46),

Para que os homens simples sejam tidos como absolutamente ignorantes, é necessário que haja quem os considere assim. Estes, como sujeitos desta definição, necessariamente a si mesmos se classificam como aqueles que sabem. Absolutizando a ignorância dos outros, na melhor das hipóteses relativizam a sua própria ignorância.

Dessa relação também (in)tensa com a tecnologia, surgiu, na turma, a ideia de fazer de sua participação no evento da EJA uma "experiência tecnológica". Resolveram produzir um vídeo para apresentar no evento e, depois, o fariam circular pelos espaços disponíveis, como nas redes sociais, por exemplo. Quase todos aceitaram. Os jovens, no entanto, declinaram. Interpretamos sua negativa no sentido de que não queriam "deixar gravada", tornando pública, a sua situação de analfabetismo.

O conteúdo do vídeo foi definido em grupo: seria um convite aos analfabetos da cidade - ou, de forma mais abrangente, àqueles que não concluíram sua escolarização no ensino fundamental - para que se encorajassem a voltar a estudar, na "nossa EJA". A partir daí, o roteiro foi elaborado, organizando as falas em três diferentes momentos: "quem sou eu" (como eu me defino, o lugar de onde falo); "como foi minha relação com a escola" (durante o período de escolarização, na infância ou em outros momentos da vida); "a EJA na minha vida" (depois que voltei a estudar, quais conquistas posso relacionar?). Estabeleceu-se que as falas deveriam ser curtas, tendo em vista que um vídeo longo não atrairia espectadores. E, assim, estava pronto o roteiro.

Tendo em vista a não participação dos três estudantes jovens e a ausência de outros estudantes nos dias de captura do material, tomaram parte, efetivamente, nove pessoas, contando com a docente e o coordenador do núcleo ${ }^{8}$.

\footnotetext{
${ }^{8}$ Como a docente não tinha habilidades técnicas de criação, produção e edição de vídeo a partir das tecnologias digitais, a mesma convidou uma amiga a dar sua contribuição. Esta, prontamente, aceitou o convite e de forma plena entrou em sintonia com o grupo e com a proposta. Em apenas dois dias, foi feita a
} 
O processo foi, como diria Paulo Freire, uma boniteza! Todos pensaram suas falas e utilizaram seu espaço de forma consciente, madura, de maneira a realmente cumprir o planejado: convencer outras pessoas, em condições similares às suas, a se encorajarem e procurarem um núcleo de EJA que pudesse lhes trazer as mesmas contribuições que a “nossa”: aprender a ler, escrever, contar, discutir, argumentar, questionar, posicionar-se, ter acesso a diferentes atividades culturais, passar por experiências relevantes, conhecer pessoas, interagir com diferentes sujeitos. Assumir, enfim, as rédeas de suas vidas também pela via da escolarização.

Cada um, com seu próprio roteiro, relatou partes de suas vivências e experiências de forma a mostrar que tiveram dificuldades, sim, mas comungavam do sentimento de que também a idade adulta tem um processo e um tempo de viver o direito à educação. Por isso, inclusive, o vídeo foi denominado "Tempo de EJA".

A edição do material foi difícil (todos os depoimentos gravados pareciam importantes demais para serem cortados) e ficou com aproximadamente 18 minutos. $O$ grupo teve consciência de que o vídeo não atingiu o resultado esperado, em termos de ser atrativo para potenciais espectadores, pois ficou bastante longo. Todavia, optamos por deixá-lo com esta extensão, tendo em vista que o trabalho resultou, em mais do que uma "produção vendável”, um lindo processo pedagógico de construção de saberes e afirmação de identidades, com vistas ao exercício da palavra - e da cidadania, ao cabo.

Como primeira atividade, após a edição do material, foi realizada uma exibição privada, exclusivamente para a turma e o coordenador do núcleo, para que pudessem opinar a seu respeito. Essa sessão tornou-se um momento verdadeiramente especial para a docente, ao vê-los ali assistindo a si próprios. Um momento que, além de emocionante, ratificou as potencialidades das tecnologias digitais: a importância de vê-los se (re)conhecendo como autores, criadores de um conteúdo inédito e potencialmente tão importante para outros. Eram protagonistas conscientes de suas próprias histórias. Foi processo de produção do vídeo. Rosane Maria Kreuch é, também, professora da Rede Municipal de Ensino de Florianópolis e Mestre em Educação, pela linha Educação e Comunicação (UFSC). Por um longo período, trabalhou no Núcleo de Tecnologia Municipal (NTM), onde participava da formação de professores da rede municipal de ensino de Florianópolis para o uso das tecnologias digitais. 
possível constatar que perceberam-se importantes agentes veiculadores de outras possibilidades - eles planejaram, desenvolveram e tiveram divulgado um conteúdo relevante e de forma sistematizada, talvez pela primeira vez em suas vidas. Constataram que suas trajetórias, suas histórias de vida, enfim, poderiam servir de exemplo, um exemplo positivo, pois desejaram e estavam realizando a superação de suas fragilidades de escolarização.

O vídeo encontra-se disponível no canal Youtube desde o final de 2013, no endereço https://youtu.be/Ko_fBhZPhXU, sob o título "Tempo de EJA" (CORD, KREUCH, 2013) contando atualmente com mais de 300 visualizações.

Desta experiência - pequena, mas significativa — puderam todos os envolvidos, e cada um à sua maneira, comemorar a comunicação desenvolvida em processo pedagógico. $E$, nesse processo, percebemos que se pode ir mais além, sem grande esforço: é totalmente possível que sujeitos como os estudantes em questão, com pouquíssima experiência no uso das tecnologias digitais, possam se assenhorar de todo o processo, do planejamento à captura, edição, divulgação e distribuição do conteúdo escolhido. Essa seria, então, uma possibilidade de conquistar espaço para exercitar a cidadania de diferentes grupos, desmistificando inclusive o uso de tecnologias digitais aparentemente pouco acessíveis.

Cabe-nos, como pesquisadoras, buscar problematizar a relação dos adultos e idosos pouco escolarizados com as tecnologias digitais e, de forma mais abrangente, com a própria cultura digital. Questões tais como: em que medida as tecnologias digitais podem contribuir, aos estudantes em processo de alfabetização da EJA, para a solidificação da conquista da cidadania plena? Como se dá a apropriação dos recursos dessas tecnologias para se transformarem em autores? Como compreendem esses cidadãos e cidadãs da EJA sua imersão e relação com a cultura digital expressa nas atuais tecnologias existentes? Como é possível generalizar experiências como estas, em classes de EJA, para que se torne mais comum o uso consciente das tecnologias digitais entre sua clientela, de forma a serem incorporados seus saberes experienciais? Ressalte-se que estas questões estão implicitamente impregnadas de conexões coletivas, tais como: rede, cooperação, colaboração, parcerias, enfim. Tornar-se autor-ator, na cultura digital e na 
vida como um todo, pressupõe aprendizagens solidárias.

\section{Faltou dizer...}

Tendo em vista a vigência da crença no poder da escola como espaço privilegiado para que o ser humano aprenda e, a partir desta aprendizagem, consiga se relacionar melhor com o mundo e suas coisas, como concebemos a vida cotidiana de sujeitos que estão (ou estiveram, por curtos ou longos períodos) fora da escola? Estariam estes sujeitos alijados totalmente do desenrolar dos processos sociais e do uso dos recursos tecnológicos, por não terem apresentado uma aprendizagem escolar satisfatória ou por não ostentarem certificações que, teoricamente, qualifique-os para essa mesma vida em sociedade?

Assumimos o pressuposto de que, mesmo em flagrante desvantagem no sentido instrucional (escolarização) e sendo considerados excluídos do acesso à grande parcela dos benefícios tecnológicos disponíveis atualmente, os adultos e idosos pouco escolarizados podem, devem e se beneficiam das tecnologias digitais para ampliar suas possibilidades de acessar a informações e conhecimentos, interagir e, também, produzir conteúdo a ser veiculado nos canais possíveis. Este conteúdo teria dupla função: ampliar as possibilidades de circulação dos próprios sujeitos pela cultura digital e ampliar sua participação cidadã em uma sociedade cada vez mais plena de informação e comunicação.

Esta dupla via, do desenvolvimento das habilidades requeridas ao mundo letrado e da incorporação das tecnologias digitais ao cotidiano dos sujeitos pouco escolarizados, ensejando cidadania, vai ao encontro do que Freire (1977, p. 69) considera ao explicitar a relação entre educação e comunicação: “A educação é comunicação, é diálogo, na medida em que não é transferência de saber, mas um encontro de sujeitos interlocutores que buscam a significação dos significados". E educação como processo comunicativo, na realidade da Educação de Jovens e Adultos, parece-nos algo perfeitamente em conformidade com o que acreditamos possível na relação pedagógica, tendo em vista que os jovens, adultos e idosos que frequentam as salas de aula da EJA já têm constituída 
uma considerável relação dialógica com o mundo e com as coisas. Nesse sentido, "a valorização dos saberes experienciais traduz uma ruptura epistemológica com uma concepção positivista de conhecimento, dicotômica; os saberes práticos não são uma mera aplicação dos saberes teóricos" (PIRES, 2008, p. 11). Os próprios sujeitos são, desta forma, integrantes e importantes atores no trabalho de educar(-se).

A apropriação plena da cultura digital, sem dúvida, apresenta-se como um desafio aos sujeitos pouco escolarizados. Mas, longe de querer minimizar seu impacto na realidade atual, podemos conceber que este é mais um desafio aos sujeitos enfocados nesta reflexão. E para quem vive de ultrapassar obstáculos potencializados pelo não domínio da cultura letrada, é possível encarar este como apenas mais um que, certamente, será superado.

\section{Referências}

BONDIA, Jorge Larrosa. Experiência e alteridade em educação. Revista Reflexão e Ação, Santa Cruz do Sul, v.19, n.2, p.04-27, jul./dez. 2011. p. 4. Disponível em <https://online.unisc.br/seer/index.php/reflex/article/view/2444/1898 >. Acesso em: 05/03/2014.

CASTELLS, Manuel. A sociedade em rede. 6. ed. São Paulo: Paz e Terra : 1999.

CAVACO, Carmen. Adultos pouco escolarizados: políticas e práticas de formação. Lisboa: EDUCA/Unidade de I\&D de Ciências da Educação, 2009.

CORD, Deisi; KREUCH, Rosane Maria et al. Tempo de EJA [Filme]. Florianópolis, 2013. Disponível em: <http://youtu.be/Ko_fBhZPhXU>.

CORTÁZAR, Júlio. Preámbulo a las instrucciones para dar cuerda al reloj. Disponível em: <http://www.me.gov.ar/efeme/cortazar/reloj.html>. Acesso: 16/03/2015.

FREIRE, Paulo. Extensão ou comunicação? 13.ed. Rio de Janeiro : Paz e Terra, 1977.

GIL, Gilberto. Aula magna proferida na Universidade de São Paulo em 10 de agosto de 2004. Disponível em: <http://www.cultura.gov.br/noticias-ancine1/lasset_publisher/QRV5ftQkjXuV/content/ministro-da-cultura-gilberto-gil-em-aula-magnana-universidade-de-sao-paulo-usp-/11025>. Acesso em:03/04/2015. 
KENSKI, Vani Moreira. Educação e tecnologias: o novo ritmo da informação. Campinas, SP: Papirus, 2007.

SANTOS, Boaventura de Sousa. Um discurso sobre as ciências. 12. ed. Porto: Afrontamento, 2001.

PIRES, Ana Luísa de Oliveira. Aprendizagem de adultos: contextos e processos de desenvolvimento e reconhecimento de competências. In: SEMINÁRIO NOVOS PÚBLICOS NO IPS: OS MAIORES DE 23 ANOS, 21 Maio 2008, Setúbal - Portugal. Anais... Setubal, PT: Escola Superior de Educação, Instituto Politécnico de Setúbal, 2008. Disponível em: $<$ http://www.ips.pt/ips_si/web_gessi_docs.download_file?p_name=F446570191/Aprendizagem de_adultos.pdf > Acesso em: 31/03/2015

VIEIRA PINTO. Álvaro. Sete lições sobre educação de adultos. 16.ed. São Paulo: Cortez,2010.

VIEIRA PINTO. Álvaro. O conceito de tecnologia. Volume I. Rio de Janeiro: Contratempo, 2005.

Recebido em: 31/05/2015 Aprovado em: 30/07/2015

Universidade do Estado de Santa Catarina - UDESC Centro de Ciências Humanas e da Educação - FAED

Revista PerCursos Volume 16 - Número 31 - Ano 2015 revistapercursos@gmail.com 